\title{
Determining Intention, Fast Food Consumption and Their Related Factors Among University Students by Using A Behavior Change Theory
}

Alireza Didarloo

Urmia University

Surur Khalili

Urmia University

Ahmad Ali Aghapour

Urmia University

Seyed Mortaza Mousavi ( $\sim$ seyed4061@gmail.com )

Urmia University

\section{Research Article}

Keywords: Fast food, Predictor, Student, Theory of Planned Behavior, Iran.

Posted Date: December 28th, 2020

DOl: https://doi.org/10.21203/rs.3.rs-118684/v1

License: (c) This work is licensed under a Creative Commons Attribution 4.0 International License.

Read Full License

Version of Record: A version of this preprint was published at BMC Public Health on February 15th, 2022. See the published version at https://doi.org/10.1186/s12889-022-12696-x. 
IT

ir

$1 \varepsilon$

$10{ }^{\S}$ Corresponding Author:

17 Seyed Mortaza Mousavi

IV

11

19

r.

r)

rr

rr

$r \varepsilon$

\section{Behavior Change Theory}

\author{
$7 \quad{ }^{1}$ Social Determinants of Health Research Center, Urmia University of Medical Sciences, The \\ $\checkmark \quad$ Province of Western Azarbaijan, Urmia, 5756115198, Iran \\ $\wedge \quad{ }^{2}$ Faculty of Health, Urmia University of Medical Sciences, the Province of Western Azarbaijan, \\ $\uparrow \quad$ Urmia, 5756115198, Iran \\ 1. ${ }^{3}$ Faculty of Paramedical Sciences, Urmia University of Medical Sciences, the Province of \\ 11 Western Azarbaijan Urmia, Postal code: 5756115198, Iran \\ Alireza Didarloo ${ }^{1}$, Surur Khalili ${ }^{2}$, Ahmad Ali Aghapour ${ }^{2}$, Seyed Mortaza Mousavi ${ }^{3 \S}$
}

Running head: Determining intention and fast food consumption

Department of Paramedical Science, School of Paramedical Sciences, Urmia University of

Medical Sciences, Urmia, Iran.

Tel. 98-4432752306

Fax. 98-4432770047

E-mail. seyed4061@gmail.com 
r.

r

rt

Th

एะ

ro

די

rV

r

rq

$\varepsilon$.

\&)

$\varepsilon r$

$\varepsilon r$

$\leqslant \varepsilon$

$\varepsilon 0$

$\varepsilon 7$

$\varepsilon V$

$\varepsilon \wedge$

$\leqslant 9$

o.

01

or

or

oร

00

\section{Abstract}

\section{Background}

Today, with the advancement of science, technology and industry, people's lifestyles such as the pattern of people's food, have changed from traditional foods to fast foods. The aim of this survey was to examine and identify factors influencing intent to use fast foods and behavior of fast food intake among students based on the theory of planned behavior (TPB).

\section{Methods}

A cross-sectional study was conducted among 229 university students. The study sample was selected and entered to the study using stratified random sampling method. Data were collected using a four-part questionnaire including Participants' characteristics, knowledge, the ТРB variables, and fast food consumption behavior. The study data were analyzed in SPSS software (version 16.0) using descriptive statistics (frequencies, Means, and Standard Deviation) and inferential statistics (t-test, Chi-square, correlation coefficient and multiple regressions).

\section{Results}

The monthly frequency of fast food consumption among students was reported 2.7 times. The TPB explained 35\%, 23\% variance of intent to use fast food and behavior of fast food intake, respectively. Among the TPB variables, knowledge $(\mathrm{r}=.340, \mathrm{p}<0.001)$ and subjective norm $(\mathrm{r}=.318, \mathrm{p}<0.001)$ were known as important predictors of intention to consume fast foods - In addition, based on regression analyses, intention $(\mathrm{r}=.215, \mathrm{p}<0.05)$, perceived behavioral control $(\mathrm{r}=.205, \mathrm{p}<0.05)$, and knowledge $(\mathrm{r}=.127, \mathrm{p}<0.05)$ were related to fast food consumption, and these relationships were statistically significant.

\section{Conclusions}

The current study showed that the TPB is a good theory in predicting intent to use fast food and the actual behavior. It is supposed that health educators use from the present study results in designing appropriate interventions to improve nutritional status of students.

Keywords: Fast food, Predictor, Student, Theory of Planned Behavior, Iran.

\section{Background}

Over the past few decades, non-communicable diseases such as eczema, asthma, cancer, type 2 diabetes, obesity, etc. have increased in developed countries [1,2]. Also, these diseases are more prevalent with increasing urbanization in developing countries $[3,4,5]$. The occurrence of many 
non-communicable diseases is related to diet [6]. Food habits are rooted from cultural, environmental, economic, social and religious factors. An effective factor in the development of chronic diseases is lifestyle, dietary patterns and habits. Inappropriate food habits and unhealthy environments have increased the incidence of non-communicable diseases in the world $[7,8]$.

Many developing countries with a tendency towards Western dietary culture go away from traditional and local diets [6]. Healthy foods with nutrients have been replaced by new foods called fast foods [9]. Fast food is the food prepared and consumed outside and often in fast food restaurants [10]. Fast food is often highly processed and prepared in an industrial fashion, i.e., with standard ingredients and methodical and standardized cooking and production methods. [10]. In fast food, vitamins, minerals, fiber and amino acids are low or absent but energy is high [9]. Fast food consumption has increased dramatically in the last 30 years in European and American countries [11].

Previous studies reported patterns of inappropriate and harmful food consumption in Iranian children and adolescents $[12,13]$. Most fast food customers are adolescents and youth, as these products are quickly and easily produced and relatively inexpensive [14]. One Iranian study shows that $51 \%$ of children eat inappropriate snacks and drinks over a week [15]. It is also reported that adults today consume fast food more than previous generations [16]. Faqih and Anousheh reported that $20 \%$ of adolescents and $10 \%$ of adults consumed sandwiches 3 or more times a week [17].

According to two studies, children and adolescents who consume fast food have received more energy, saturated fat, sodium, carbohydrates and more sugar than their peers, but they have less fiber, vitamin A and C, and less fruit and vegetables [18, 19]. Also, because of the use of oils to fry these foods at high temperatures, these types of foods may contain toxic and inappropriate substances that threaten the health of consumers [20].

In a study in the United States on young people between 13 and 17 years old, it was found that there is a significant relationship between weight gain and obesity with pre-prepared foods [21].According to the Center for Disease Control and Prevention (2007-2008), 17\% of children aged 2 to 19 years and 34\% of those aged 20 years and older were obese [22]. Many Health problems were caused by human health behavior(e.g. exercising regularly, eating a balanced diet, 
$1 \ldots$

$1 \cdot 1$

$1 \cdot r$

$1 \cdot r$

$1 \cdot \varepsilon$

1.0

1.7 $1 \cdot V$

$1 \cdot 1$

\section{$1.9 \quad$ Methods}

\section{Subjects}

and obtaining necessary inoculations, etc.) and studying behavior change theories/models provides a good insight into the causes and ways of preventing these problems [23]. One of these theories is the Theory of Planned Behavior (TPB), which is a developed form of the Theory of reasoned action (TRA), and describes a healthy behavior that is not fully under the control of a person [24].This theory can successfully predict eating habits and behaviors, and recently this theory has received considerable attention from researchers in identifying norms and beliefs related to the use of fast food [25].

Based on the TPB, intention to conduct a behavior with following three concepts is controlled: 1.Attitudes (positive and negative evaluation of a behavior), 2.Subjective norms (social pressure received from peers, family, health care providers for doing or not doing a given health behavior), 3. Perceived behavior control (This refers to a person's perception of the ease or difficulty of performing the behavior of interest.) [26, 27,28].

The TPB has been tested on different behaviors such as healthy food choice [31], physical activity [29], and fast food consumption [30]. For instance, the study conducted by Seo et al. showed that fast food consumption behavior was significantly associated with behavioral intention and perceived behavioral control. In addition, their findings highlighted that behavioral intention was significantly related to subjective norm and perceived behavioral control [28].

According to the mentioned materials, the researchers decided to test the study with the aim of investigating and explaining the intention and behavior of fast food consumption and their related factors based on the TPB among Urmia University of Medical Sciences students. The results of this study will increase the awareness and knowledge about fast food and, in addition, its results can be used in research, hospitals and healthcare settings. 
111

114

111

$11 \varepsilon$

110

117

$11 \mathrm{~V}$

111

119

IT.

$|Y|$

ITY

rr

ITE

ITO

IrT

ITV

ITA

149

M.

|T|

ITr

אזו

ITE

TH

דו

ITV

N

1

This cross-sectional study was performed on students of Urmia University of Medical Sciences located in northwest Iran in academic year of 2018-2019. The inclusion criteria for the study are girls and boys who studied at Urmia University of Medical Sciences, and students' voluntary participation in the study and obtaining written consent from the students and University principals for the students' participation in the study. The lack of willingness to continue participating in the study and not signing the informed consent form were considered as exclusion criteria.

According to the results of the study of Yar Mohammadi and et al [32], with a 95\% confidence interval and an error of 0.05 , using the formula for estimating the proportion in society, taking into account the $10 \%$ drop rate, sample size was estimated 330students. A randomized stratified sampling method was used to select the study samples. The study sample was randomly selected from each of the strata based on the share of the total sample.

\section{Questionnaire}

The data gathering tool in this study was a self-reported questionnaire, which was designed according to the existing measures in scientific literature. The study instrument was translated from English to Persian using a standard forward-backward translation technique [33]. The original instrument was translated by a bilingual specialist. The Persian version was then retranslated into English by two independent bilingual professionals to assess retention of the original meaning in the source language. Subsequently, translators worked separately in the translation process and then prepared the final version of the Persian translation. Content validity of The Persian version of questionnaire was evaluated by a panel of experts such as 3 nutrition specialists, 3 health education specialists, and 2 instrument designers. After receiving their comments, crucial revisions were conducted in the study tool. Finally, validity of the study instrument was confirmed. The present questionnaire including four following sections:

\section{General characteristics}

The first part contains personal information such as age, gender, weight, height, field of study, student education, father's education, mother's education, father job, mother's job, ethnicity, marital status, participating in nutrition educational classes, students' monthly income, family's monthly income, housing status, information resource for healthy nutrition. 
$1 \leqslant$.

$1 \leq 1$

$1 \leqslant r$

$1 \leqslant r$

$1 \leqslant \varepsilon$

$1 \leq 0$

$1 \leq 7$

$I \leqslant \vee$

$1 \leqslant \wedge$

$1 \leqslant 9$

10.

101

$10 Y$

lor

$10 \leqslant$

100

107

lov

101

109

17.

171

174

174

175

170

177

\section{Constructs of the TPB}

The second part contains questions about the constructs of the theory of planned behavior (attitude, subjective norms, perceived behavioral control and behavioral intention).In general, attitudes, subjective norm and perceived behavioral control of students were measured using indirect items. The internal reliability of all subscales of the TPB variables was good, with a Cronbach's alpha of 0.852 .

\section{Attitude toward fast food use}

The attitude of the people was evaluated using 28 indirect items (14 items of behavioral beliefs, 14 items of expectations evaluation) based on five-point the Likert scale (from strongly agree to strongly disagree) or (from very important to not at all important), and the score of each item varied from 1 to 5. The minimum and maximum score for the attitude subscale was 14 and 350, respectively. The internal reliability of attitude subscale was good, with a Cronbach's alpha of 0.778 .

\section{Subjective norm}

Subjective norms of students were measured by 10 indirect items ( 5 items of normative beliefs, 5 items of motivation to comply) based on five-point the Likert scale (from strongly agree to strongly disagree) or (from very important to not at all important), and the score of each item varied from 1 to 5 . The minimum and maximum score for the subjective norm subscale was 5 and 125 , respectively. The internal reliability of subjective norm subscale was good, with a Cronbach's alpha of 0.726 .

\section{Perceived behavioral control}

Perceived behavioral control were measured by 18 indirect items ( 9 items of control beliefs, 9 items of perceive power) based on five-point the Likert scale (from strongly agree to strongly disagree) or (from extremely difficult to extremely easy), and the score of each item varied from 1 to 5 . The minimum and maximum score for the perceived behavioral control subscale was 9 and 225, respectively. The internal reliability of subscale of perceived behavioral control was good, with a Cronbach's alpha of 0.815 . 
$17 V$

171

179

IV.

IVI

IVT

IVT

IV

ivo

IVT

IVV

IVA

$1 \times 9$

11.

111

inr

INT

$1 \wedge \varepsilon$

110

114

INV

111

119

19.

191

\section{Behavioral intention}

Behavioral intention was evaluated by 8 items based on five-point the Likert scale (from strongly agree to strongly disagree), and the score of each item varied from 1 to 5 . The minimum and maximum score for the Behavioral intention subscale was 8 and 40, respectively. The internal reliability of behavioral intention subscale was good, with a Cronbach's alpha of 0.821 .

\section{Knowledge of participants}

And the third and fourth parts are items related to food knowledge and fast food behavior. Students' knowledge of fast food was evaluated by 14 items, and the score of each item varied from 0 to 2. The minimum and maximum score for the knowledge subscale was 0 and 28, respectively. The internal reliability of students' knowledge was good, with a Cronbach's alpha of 0.783 .

\section{Fast food use}

Students' fast food consumption was assessed by frequency of use in a past month. The term "Fast food" was defined as hamburgers, doughnuts, hot dog, snack, pizza, fried chicken and fried potatoes. The frequency of fast food use was analyzed for each food category.

\section{Statistical analyses}

All statistical analyzes were performed using SPSS 16.0 software. Descriptive statistics methods such as frequencies, means and standard deviations were used along with independent $\mathrm{t}$ and $\chi^{2}$ tests. Pearson correlation test was used to investigate the relationship between TPB variables with intent to use fast food and the real use of fast food. Multiple regressions were used for further analysis. 
iqr Results

$19 \varepsilon \quad$ Descriptives

190 A total of 330 students were selected and recruited to the study, but some subjects ( 31 samples) 197 were excluded from the study due to incomplete questionnaires (21cases), and no return of I $9 \mathrm{~V}$ questionnaires (10 cases). Statistical analyses were performed on 229 students. Of these, $28.4 \%$ 191 of the students were boys and $71.6 \%$ were girls. The results of the study showed that the average 199 age for all the students was $22.10 \pm 3.30$ (the average age for male and female sexes were $22.66 \pm$ $r . . \quad 4.47$ and $21.84 \pm 2.50$, respectively). The two sexes differed in terms of BMI, so that the mean of $r \cdot 1$ BMI was higher in boy students than in girls, and this difference was statistically significant. $r \cdot r$ Almost more than 72 percent of the students had normal weight, and $28 \%$ of subjects were in r.r other weights. Approximately 20.51\%, 54.50\%, 79.77\% of the students reported the professional r. $\varepsilon$ doctoral degree, Azeri ethnicity and single.

r.o In addition, findings revealed that 64.90 percent of the participants lived in the dormitory, and $r .435 .10 \%$ of them lived in personal or rental housing. The most common level of education for $r \cdot \vee$ father $(37.10 \%)$ and mother $(44.10 \%)$ of students was diploma. Nearly, $46.50 \%$ of students $r \cdot \wedge$ gained food information (especially fast food) from health care providers, while $53.50 \%$ of them r.9 received their food information from other sources. Most students had zero monthly income, but r. $\quad 61.61$ percent of the students reported their family's monthly income more than 50 million Rials YI and $38.39 \%$ of their family had income lower than the mentioned amount. Table 1 provides ir detailed information on students' characteristics.

rit

r)

ro

YIT 


\begin{tabular}{|c|c|c|c|c|c|}
\hline \multirow[t]{2}{*}{ Variable } & \multirow{2}{*}{$\begin{array}{c}\text { The whole } \\
\text { group }\end{array}$} & \multicolumn{2}{|c|}{ Sex group } & \multirow[t]{2}{*}{$\chi^{2}$ value } & \multirow[t]{2}{*}{ p.value } \\
\hline & & $\begin{array}{c}\text { Male( }(85) \\
\text { N }(\%) \\
\end{array}$ & $\begin{array}{c}\text { Female(214) } \\
\text { N }(\%)\end{array}$ & & \\
\hline $\begin{array}{l}\text { Body weight status } \\
\text { Underweight (less than 18.5) } \\
\text { Normal (between } 18.5 \text { and } 24.9 \text { ) } \\
\text { Overweight (Between } 25 \text { and 29.9) } \\
\text { Obese (more than 29.9) }\end{array}$ & $\begin{array}{c}23(7.70) \\
216(72.20) \\
52(17.40) \\
8(2.70)\end{array}$ & $\begin{array}{c}2(0.33) \\
53(17.70) \\
25(8.35) \\
5(1.66)\end{array}$ & $\begin{array}{c}21(7.01) \\
163(54.94) \\
27(9.01) \\
3(1.00)\end{array}$ & 20.44 & $<0.001$ \\
\hline $\begin{array}{l}\text { Student education level } \\
\text { Bachelor } \\
\text { Masters } \\
\text { The professional doctor } \\
\end{array}$ & $\begin{array}{c}142(47.50) \\
4(1.30) \\
153(51.20) \\
\end{array}$ & $\begin{aligned} & 37(12.37) \\
& 2(0.67) \\
& 46(15.36) \\
&\end{aligned}$ & $\begin{array}{c}105(35.13) \\
2(0.67) \\
107(35.80) \\
\end{array}$ & 1.50 & 0.47 \\
\hline $\begin{array}{l}\text { Ethnicity } \\
\text { Turkish } \\
\text { Kurdish } \\
\text { Other } \\
\end{array}$ & $\begin{array}{l}163(54.50) \\
98(32.80) \\
38(12.70) \\
\end{array}$ & $\begin{array}{c}46(15.36) \\
30(10.02) \\
9(3.00) \\
\end{array}$ & $\begin{array}{c}117(39.22) \\
68(22.72) \\
29(9.68) \\
\end{array}$ & 0.65 & 0.72 \\
\hline $\begin{array}{l}\text { Marital status } \\
\text { Single } \\
\text { Married } \\
\end{array}$ & $\begin{array}{c}238(79.60) \\
61(20.40) \\
\end{array}$ & $\begin{array}{c}68(22.72) \\
17(5.67) \\
\end{array}$ & $\begin{array}{c}170(56.92) \\
44(14.69) \\
\end{array}$ & 0.01 & 0.91 \\
\hline $\begin{array}{l}\text { Housing } \\
\text { Personal home } \\
\text { Dorm } \\
\text { Rented home } \\
\end{array}$ & $\begin{array}{c}88(29.40) \\
194(64.90) \\
17(5.70) \\
\end{array}$ & $\begin{array}{c}23(7.68) \\
58(19.37) \\
4(1.33) \\
\end{array}$ & $\begin{array}{c}65(21.71) \\
136(45.42) \\
13(4.34) \\
\end{array}$ & 0.63 & 0.72 \\
\hline $\begin{array}{l}\text { Mother's education level } \\
\text { Illiterate } \\
\text { Diploma and under diploma } \\
\text { Bachelor } \\
\text { Masters } \\
\text { Doctor } \\
\end{array}$ & $\begin{array}{l}46(15.40) \\
132(44.10) \\
62(20.70) \\
46(15.40) \\
13(4.30) \\
\end{array}$ & $\begin{array}{l}20(6.68) \\
28(9.35) \\
20(6.68) \\
12(4.00) \\
5(1.67) \\
\end{array}$ & $\begin{array}{c}26(8.68) \\
104(34.73) \\
42(14.02) \\
34(11.35) \\
8(2.67) \\
\end{array}$ & 9.71 & 0.04 \\
\hline $\begin{array}{l}\text { Father's education level } \\
\text { Illiterate } \\
\text { Diploma and under diploma } \\
\text { Bachelor } \\
\text { Masters } \\
\text { The doctor }\end{array}$ & $\begin{array}{l}30(10.00) \\
111(37.10) \\
77(25.80) \\
60(20.10) \\
21(7.00) \\
\end{array}$ & $\begin{array}{l}16(5.34) \\
22(7.34) \\
22(7.34) \\
17(5.67) \\
8(2.67)\end{array}$ & $\begin{array}{c}14(4.67) \\
89(29.72) \\
55(18.37) \\
43(14.36) \\
13(4.34) \\
\end{array}$ & 14.5 & 0.007 \\
\hline $\begin{array}{l}\text { Father's job } \\
\text { Worker } \\
\text { Employee } \\
\text { Unemployed } \\
\text { Free job } \\
\text { The doctor } \\
\end{array}$ & $\begin{aligned} & 7(2.30) \\
& 122(40.80) \\
& 27(9.00) \\
& 134(44.80) \\
& 9(3.00) \\
&\end{aligned}$ & $\begin{array}{c}4(1.33) \\
32(10.68) \\
9(3.00) \\
3712.35) \\
3(1.00)\end{array}$ & $\begin{array}{c}3(1.00) \\
90(30.06) \\
18(6.01) \\
97(32.39) \\
6(2.00) \\
\end{array}$ & 3.59 & 0.46 \\
\hline $\begin{array}{l}\text { Mother's job } \\
\text { Worker } \\
\text { Employee } \\
\text { Housewife } \\
\text { Free job } \\
\text { The doctor } \\
\end{array}$ & $\begin{array}{c}6(2.00) \\
67(22.40) \\
96(32.10) \\
123(41.10) \\
7(2.30) \\
\end{array}$ & $\begin{array}{c}3(100) \\
19(6.34) \\
22(7.34) \\
39(13.02) \\
2(0.67) \\
\end{array}$ & $\begin{array}{c}3(1.00) \\
48(16.06) \\
74(24.71) \\
84(28.05) \\
5(1.67) \\
\end{array}$ & 3.45 & 0.48 \\
\hline $\begin{array}{l}\text { Participate in nutrition education class } \\
\text { Yes } \\
\text { No }\end{array}$ & $\begin{array}{l}106(35.50) \\
193(64.50)\end{array}$ & $\begin{array}{l}35(11.69) \\
50(16.70)\end{array}$ & $\begin{array}{c}71(23.71) \\
143(47.76)\end{array}$ & 1.71 & 0.19 \\
\hline $\begin{array}{l}\text { The source of nutritional information } \\
\text { Health care personnel } \\
\text { Family and friends } \\
\text { Radio and TV } \\
\text { Book, magazine and newspaper } \\
\text { Other }\end{array}$ & $\begin{array}{l}139(46.50) \\
47(15.70) \\
48(16.10) \\
33(11.00) \\
32(10.70) \\
\end{array}$ & $\begin{array}{c}40(13.36) \\
13(4.34) \\
13(4.34) \\
5(1.67) \\
14(4.67) \\
\end{array}$ & $\begin{array}{l}99(33.06) \\
34(11.35) \\
35(11.69) \\
28(9.35) \\
18(6.01) \\
\end{array}$ & 6.61 & 0.16 \\
\hline $\begin{array}{l}\text { Student monthly income } \\
\text { Zero } \\
\text { Less than 2000,000 Rials } \\
\text { Between 2000,000 and 3499,000Rials } \\
\text { Between } 3500,000 \text { and 5000,000 Rials } \\
\text { More than 5000,000 Rials }\end{array}$ & $\begin{array}{c}238(79.60) \\
22(7.40) \\
10(3.30) \\
9(3.00) \\
20(6.70) \\
\end{array}$ & $\begin{array}{c}56(18.70) \\
12(4.00) \\
5(1.67) \\
2(0.67) \\
10(3.34) \\
\end{array}$ & $\begin{array}{c}182(60.78) \\
10(3.34) \\
5(1.67) \\
7(2.30) \\
10(3.34)\end{array}$ & 17.21 & 0.002 \\
\hline $\begin{array}{l}\text { Family monthly income } \\
\text { Less than 20,000,000 Rials } \\
\text { Between 20,000,000 and 34,990,00 0Rials } \\
\text { Between 35,000,000 and 50,000,000Rials } \\
\text { More than 50,000,000 Rials }\end{array}$ & $\begin{array}{c}37(12.40) \\
50(16.70) \\
28(9.40) \\
184(61.50)\end{array}$ & $\begin{aligned} 18 & (6.01) \\
9 & (3.00) \\
7 & (2.30) \\
51 & (17.03)\end{aligned}$ & $\begin{array}{c}19(6.34) \\
41(13.69) \\
21(7.01) \\
133(44.42)\end{array}$ & 10.31 & 0.015 \\
\hline
\end{tabular}


$r r$.

TrI

TrY

TYT

TrE

TrO

\begin{tabular}{|c|c|c|c|c|c|}
\hline \multirow[t]{3}{*}{ Variable } & \multirow[t]{2}{*}{ The whole group } & \multicolumn{2}{|c|}{ Sex group } & \multirow[t]{3}{*}{$t$ value } & \multirow[t]{3}{*}{ p.value } \\
\hline & & Male & Female & & \\
\hline & ${ }^{\mathrm{a}} \mathrm{M} \pm \mathrm{SD}^{\mathrm{b}}$ & $\mathrm{M} \pm \mathrm{SD}$ & $\mathrm{M} \pm \mathrm{SD}$ & & \\
\hline Knowledge & $21.68 \pm 5.26$ & $21.15 \pm 5.06$ & $21.89 \pm 5.33$ & 1.09 & 0.27 \\
\hline Attitude & $190.30 \pm 43.54$ & $188.42 \pm 40.08$ & $191.06 \pm 44.90$ & 0.47 & 0.63 \\
\hline Subjective norm & $55.15 \pm 13.10$ & $55.69 \pm 13.51$ & $54.93 \pm 12.96$ & -0.44 & 0.65 \\
\hline Perceived behavioral control & $98.13 \pm 36.52$ & $101.61 \pm 39.80$ & $96.75 \pm 35.14$ & -1.04 & 0.30 \\
\hline Behavioral intention & $27.96 \pm 6.19$ & $28.21 \pm 6.86$ & $27.86 \pm 5.92$ & -0.43 & 0.66 \\
\hline Fast-food consumption & $2.70 \pm 3.91$ & $2.97 \pm 4.58$ & $2.57 \pm 3.61$ & -0.79 & $\overline{0.43}$ \\
\hline
\end{tabular}

YrT

TrV

rYA

rrq

rT.

TrT

rTt

Trt

tre

rro

rTy

rTV

rTh

rrq

$r \varepsilon$.

$r \leq 1$

$r \leqslant Y$

$r \leqslant r$

\section{Main analysis}

Table 2 presents the mean score of knowledge and variables of the study-related theoretical framework. As the mean score of subjective norm, perceived behavioral control and behavioral intention in male students compared to female students was high, but those were not significant statistically $(\mathrm{p}>0.05)$.

Table2. The mean score of knowledge and the constructs of the TPB among students in terms of sex

a. Mean, b. Standard Deviation

Some variables of the TPB were significantly correlated with each other $(\mathrm{P}<0.01$, Table 3$)$. In particular, fast food consumption behavior was highly $(\mathrm{r}=0.382)$ correlated with behavioral intention. Multiple regression analyses were conducted to determine the relative importance of the variables of the TPB to behavioral intention and fast food consumption behavior (Tables 4 , 5).In these analyzes, when the attitude toward behavior, subjective norms, and perceived control was regressed to behavioral intention, the model was very significant $(\mathrm{P}=0.000)$ and explained 0.347 of variance of behavioral intention. While attitude and perceived behavioral control were not significant, the subjective norms and students' knowledge were significantly related to the intention to eat fast food. It seems that subjective norms and students' knowledge to be the most important predictors of behavioral intent. Table 4 shows more information about predictors of behavioral intention.

The second model, using fast food consumption as a dependent variable, was also very significant $(\mathrm{P}=0.000)$, and explained nearly a quarter of the variance $(0.231)$ of fast food consumption. Both behavioral intention and perceived behavioral control were significantly associated with fast food consumption, of which behavioral intention appeared to be more important. Table 5 presents more information about predictors of fast food consumption. 


\begin{tabular}{|l|l|l|l|l|l|l|}
\hline Variable & Behavioral intention & Fast-food consumption & Knowledge & Attitude & Subjective norm & Perceived behavioral control \\
\hline Behavioral intention & 1.00 & & & & & \\
\hline Fast-food consumption & $.382^{* *}$ & 1.00 & & & & \\
\hline Knowledge & $.355^{* *}$ & $.234^{* *}$ & 1.00 & & & \\
\hline Attitude & .068 & $.215^{* *}$ & -.111 & 1.00 & & \\
\hline Subjective norm & $.351^{* *}$ & .055 & .073 & $.292^{* *}$ & 1.00 & \\
\hline Perceived behavioral control & .037 & $.291^{* *}$ & $-.276^{* *}$ & $.539^{* *}$ & $.325^{* *}$ & \\
\hline
\end{tabular}

r₹า ** $\mathrm{p}<0.01$

$r \leqslant \vee$

Table4. Multiple linear regression analysis on students' behavioral intention

\begin{tabular}{|c|c|c|c|c|c|c|}
\hline \multirow[t]{2}{*}{ Model 1} & \multicolumn{2}{|c|}{$\begin{array}{c}\text { Unstandardized } \\
\text { Coefficients }\end{array}$} & \multirow{2}{*}{$\begin{array}{c}\text { Standardized } \\
\text { Coefficients }\end{array}$} & \multirow[t]{2}{*}{ t-value } & \multirow[t]{2}{*}{$\begin{array}{c}\text { p- } \\
\text { value }\end{array}$} & \multirow[t]{2}{*}{$\mathbf{R}^{2}$} \\
\hline & B & Std. Error & & & & \\
\hline Constant & 10.582 & 2.222 & & 4.762 & .000 & \multirow[t]{5}{*}{0.347} \\
\hline Knowledge & .400 & .064 & .340 & 6.292 & .000 & \\
\hline Attitude & .000 & .009 & -.002 & -.038 & .970 & \\
\hline Subjective norm & .005 & .011 & .318 & 5.726 & .000 & \\
\hline Perceived behavioral control & .150 & .026 & .029 & .441 & .659 & \\
\hline
\end{tabular}

$r \leqslant \wedge$

$r \varepsilon q$

Table5.Multiple linear regression analysis on students' fast food consumption behavior

\begin{tabular}{|c|c|c|c|c|c|c|}
\hline \multirow[t]{2}{*}{ Model2 } & \multicolumn{2}{|c|}{ Unstandardized Coefficients } & \multirow{2}{*}{$\begin{array}{c}\text { Standardized Coefficients } \\
\text { Beta }\end{array}$} & \multirow[t]{2}{*}{ t-value } & \multirow[t]{2}{*}{ p-value } & \multirow[t]{2}{*}{$\mathbf{R}^{2}$} \\
\hline & B & Std. Error & & & & \\
\hline Constant & 2.804 & 1.556 & & 1.802 & .073 & \multirow[t]{6}{*}{0.231} \\
\hline Knowledge & .094 & .046 & .127 & 2.061 & .040 & \\
\hline Attitude & .009 & .006 & .095 & 1.456 & .146 & \\
\hline Subjective norm & .003 & .019 & .010 & .161 & .872 & \\
\hline Perceived behavioral control & .022 & .007 & .205 & 2.967 & .003 & \\
\hline Behavioral intention & .013 & .002 & .215 & 3.155 & .000 & \\
\hline
\end{tabular}

ro.

Yo1

ror Discussion

ror This investigation was conducted on a sample of university students to assess the status of their

ros fast-food consumption. It also examined the factors affecting behavioral intent and fast food roo consumption by applying the TPB. The results of the present study showed that students ror consumed fast food at an average of 2.7 times a month. Fast food in male students was often 
rov

roN

roq

r.

(4)

rTY

rד

rา

rTo

rTד

rTV

YTA

r79

rv.

rVI

TVY

rVT

rVE

rVo

YVT

rVV

rVA

rvq

YA.

rNI

YAY

rN

Y人E

r人o

YNT

reported more than female students. A study on fast food consumption among students at Daejeon School reported monthly frequencies of fast food types: 2.7 for burgers, 2.1 for French fries, 1.8 for chicken [34].Results of Kim study and other similar researches [35, 32] approximately were in line with findings of the present study.

Given that most men do not have the time and skill to make traditional foods, and because of a lot of work, they prefer to turn to fast-foods, and so they are more likely to use fast foods. Meanwhile, the results of some studies indicate that most women are not very happy from high weight and are more likely to reduce their weight [36].Therefore women do not have a positive attitude toward obesogenic foods compared to men [37], which can be a reason for consuming less fast food among women. Instead, the results of a study done by Seo et al. In Korea indicated that fast food consumption among high school students was 4.05 times a month and this consumption was reported among boys more than girls [28]. The results of the Korean study were contrary to the results of the study, meaning that fast food in Korean samples was more than Iranian. The reason for this difference can be traced to factors such as sample size, cultural, social, and economic characteristics of the samples.

Performing and not performing the behavior by a person is a function of several factors based on the theory of planned behavior. One of these factors is the person's intention and desire to do the behavior. Behavioral intention itself is also affected by factors such as attitude, students' knowledge, social pressure, and perceived behavioral control. In the present study, based on linear regression analysis, students' knowledge and social pressure were both related to their intention and consume fast foods. That is, students who had the necessary information about nutrition, especially fast foods, had a high intent to choose and consume foods.

Several studies have examined the relationship between knowledge of foods and their contents and attitudes toward fast foods and processed foods or relationship between attitudes toward food additives and food choice behavior [38, 39, 40, 41].Aoki et al. [38] found that information about food and its contents positively or negatively affects attitudes and intentions towards food. They pointed out that food information was important for consumers in choosing food. Back and Lee [42] found that consumers had inadequate and incorrect information about foods, which could affect their attitudes or intent. These studies suggest that providing more information about foods and their compounds can help them to improve their attitude towards foods. Therefore, 
rAV

Yᄉᄉ

rᄉq

rq.

(9)

rar

rqu

rqะ

r9o

r97

rqV

ras

rqq

r..

r.

$r \cdot r$

r.

$\Gamma \cdot \varepsilon$

r.o

r.

$r \cdot v$

r.

r.

ए.

ए

ri



ए)

TI

training on the performance, benefits and safety of foods, including positive and negative sides, should prevent misunderstandings about food supplements and reduce food safety concerns.

The findings of the present investigation showed that subjective norms of students were effective on intent to use fast foods. Friends had the most impact on the plan to eat fast foods, as expected. In addition, the normative beliefs of students were also more positive for friends than family and teachers. This conclusion suggests that most training programs should focus on their friends as a critical group that may affect intent to use fast foods.

Results of some previous studies were similar to findings of the current study. One study conducted by Mirkarimi et al. highlighted that subjective norms had the main role on students' intent to use fast foods [43]. In the other words, they found that behavioral intention was affected by subjective norms. In addition, the study of Yarmohammadi and et al showed that subjective norms predict intention and behavior [32].

In this study, TPB demonstrated to be a sound conceptual framework for explaining closely $35 \%$ of the variance in students' behavioral intention to consume fast-food. Among the TPB variables, subjective norm and knowledge of students were the most important predictors of intention to use fast foods. These findings are consistent with other results that identify that subjective norms have a significant effect on consuming fruits and vegetables [44]. In study of Lynn Fudge, Path analysis highlighted that TPB explained adolescent fast-food behavioral intention to consume fast food. The model identified subjective norms had the strongest relationship with adolescent behavioral intention to consume fast food [45].

The results of this study showed that the attitude toward fast food behavior did not predict intent and the behavior. However, some studies have reported contradictory findings with the study. For example, the findings of Stefanie and Chery's study showed that attitude was a predictor for intent to use healthy nutrition [46]. Yarmohammadi and colleagues stated in their study that attitude was the most important predictor of behavioral intent [32]. In the study of determinants of fast food intake, Dunn et al. has identified attitude as a predictor of the intent of fast food consumption [47]. The results of studies by Seo et al., Ebadi et al., along with the findings of this study, showed that attitude toward fast food consumption is not significantly related to behavioral intention $[28,48]$.Based on the findings of the current study, fast-food consumption 
T17 of students was also influenced by some the TPB variables. Multiple linear regression analyses

IV revealed that the constructs of the TPB explained fast food use behaviors with R-squared $\left(\mathrm{R}^{2}\right)$ of

५ $1 \wedge$ 0.23. In these analyses, intention, perceived behavioral control, and knowledge were known as

19 effective factors on fast-food consumption. Among the TPB constructs, behavioral intention was

rr. the most important predictor of fast-food consumption. The intention plays a fundamental role in

rr) the theory of planned behavior. The intentions include motivational factors that influence

rr behavior and show how much people want to behave and how hard they try to do the behavior

[49]. In study Ebadi et al., regression analysis showed the intention as a predictor of fast food rrs consumption behavior [48].In studies of Stefanie et al and Seo et al, has reported intention as rro correlate of the behavior $[46,28]$. All these studies confirmed and supported this part of our rr study findings. In addition, the results indicated that perceived behavioral control directly

rrV

TrA

rrq

משת

וT

Trt

Trt

rTs

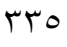

דיזי

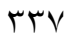

TrN



$r \varepsilon$.

$r \leqslant 1$

$r \leqslant r$

$r \leqslant T$

$r \leq \varepsilon$

$r \leqslant 0$ influenced the behavior of fast-food consumption. Some investigations confirmed this portion of our results. For instance, the results of Dunn et al. showed that perceived behavioral control (PBC) and intent predicted the behavior of fast food consumption [47]. Also, in the study of Seo et al., regression analysis showed that fast food consumption behavior was correlated with perceived behavioral control [28].Yarmohammadi et al. found that in predicting behavior, perceived behavioral control along with intention could predict $6 \%$ of behavior [32]. Although this study provides valuable knowledge regarding the relationships between behavioral intent and TPB variables, this study, like other studies, has a number of limitations. First, a crosssectional study was used to examine the relationship between the variables. Due to the fact that in cross-sectional studies, all data are collected in a period of time, as a result, these studies do not have the necessary ability to examine the cause-and-effect relationships between variables. Second, the results of this type of study can only be generalized to populations with similar characteristics and have no generalizability beyond that. Third, since the data of this study were collected using the self-report questionnaire, the respondents may have errors and bias in completing the questionnaire and this can affect the results of the study.

\section{Conclusions}

In sum, this study was conducted to identify factors influencing intention and behavior of fastfood consumption among students by using the theory of planned behavior. The findings revealed that changeability of students' intention to use fast food and their real behavior is 
$r \leqslant 4$ dependent on the TPB variables. As this theoretical framework explained 35\%, 23\% of intent to $r \leqslant v$ consume fast-foods and fast-food consumption, respectively. Among the TPB constructs, $r$ $\longleftarrow \wedge$ knowledge and subjective norm were known as the most important predictors of intention to use $r \leqslant 9$ fast foods. In addition, the results indicated that intention and perceived behavioral control were ro. the most important factors influencing consumption of fast foods among participants. It is ro) imperative that health educators and promoters use these results in designing suitable educational ror interventions to improve people's nutritional behavior.

\section{ror Abbreviations}

ros TPB: Theory of Planned Behavior; TRA: Theory of Reasoned Action; SPSS: Statistical Package roo for Social Sciences; BMI: Body Mass Index

ror Ethics approval and consent to participate

rov Research has been presented in the ethics committee of Urmia University of Medical Sciences and has ro1 received the code of ethics (IR. UMSU.REC.1397.43). informed consent was obtained from all ro9 participants in this study, and all provisions of the Helsinki Statement on Research Ethics were rч. considered.

чч) Acknowledgements

rar The article authors hereby express their gratitude to Vice Chancellors for Research of Urmia Uriversity of Medical Sciences and Education Department for supporting this study.

\section{rฯ Conflict of interest}

rıo The authors declared no conflict of interest.

\section{rчr Authors'contributions}

rq All authors contribute in conceive, design of this study. A.D, S.K, A.A and S.M contributed to rл the design and implementation of the research, to the analysis of the results and to the writing of rqq the manuscript.

\section{rv. Funding}

rV The present article is the result of a proposal approved by the Vice Chancellor for Research at rvr Urmia University of Medical Sciences (No: 2017-2323). 


\section{rVT Availability of data and materials}

rvs The datasets generated during and/or analyzed during the current study arenot publicly available

rvo due to confidentiality of data and subsequent research,but are available from the corresponding

$r \vee \checkmark$ author on reasonable request.

rv Consent for publication

rvA Not applicable.

rq Competing interests

r^. None of the authors have any competing interests.

NI

rNY

rAT References

r^ะ 1. ISAAC Steering Committee. Worldwide variation in prevalence of symptoms of asthma,

rıo allergic rhino conjunctivitis, and atopic eczema: ISAAC. Lancet 1998; 351:1225-32.

rᄉr 2. Anonymous. Variations in the prevalence of respiratory symptoms, self-reported asthma rNv attacks, and use of asthma medication in the European Community Respiratory Health Survey ґ^^ (ECRHS). EurRespir J 1996; 9:687-95.

rıq 3. Hijazi N, Abalkhail B, Seaton A. Diet and childhood asthma in a society in transition: a study чq. in urban and rural Saudi Arabia. Thorax 2000; 55:775-9.

rq) 4. Asher MI, Montefort S, Björkstén B, et al. Worldwide time trends in the prevalence of ras symptoms of asthma, allergic rhinoconjunctivitis, and eczema in childhood: ISAAC Phases One rqu and Three repeat multicountry cross-sectional surveys. Lancet 2006; 368:733-43.

rqะ 5. Beaglehole R, Bonita R, Horton R, et al. Priority actions for the non-communicable disease r१० crisis. Lancet $2011 ; 377: 1438-47$.

гач 6. Devereux G. The increase in the prevalence of asthma and allergy: food for thought. Nature rqv Rev Immunol 2006; 6:869-74. 
rqu 7. Nazari B, Asgari S, Sarrafzadegan N, et al. Evaluation and types of fatty acids in some of the ५१९ most consumed foods in Iran. Journal of Isfahan Medical School 2010; 27 (99): 526-34.

«.. 8. Word Health Organization (WHO). Diet, nutrition and the prevention of chronic diseases «. 1 report of a joint WHO/FAO expert consultation. Geneva: WHO.2003. Available at: ¿.r http://whqlibdoc.who.int/publications/9241590416.pdf. [Accessed Jun 21, 2011].

¿.r 9. Ashakiran S, Deepthi R. Fast foods and their impact on health. JKIMSU 2012; 1 (2):7-15.

$\varepsilon \cdot \varepsilon$ 10. Vaida N. Prevalence of fast food intake among urban adolescent students. IJES 2013; ¿.० 2(1):353-359.

¿.7 11. Bowman SA, Vinyard BT. Fast food consumption of US adults: impact on energy and \&.V nutrient intakes and overweight status. Journal of the American College of Nutrition 2004; ¿.^ 23(2):163-8.

¿.q 12. Abdollahi M, Amini M, Kianfar $\mathrm{H}$, et al. Qualitative study on nutritional knowledge of \&. primary-school children and mothers in Tehran 2008; 14(1): 82-89.

\&) 13.Shahanjarini A, Shojaezadeh D, Majdzadeh R, et al. Application of an integrative approach to \&ir identify determinants of junk food consumption among female adolescents. Iranian Journal of \&IT Nutrition Sciences \& Food Technology 2009; 4(2):61-70.

\& $\leqslant$ 14. Lee JS. A comparative study on fast food consumption patterns classified by age in Busan. \&10 Korean Journal of Community Nutrition 2007; 12(5):534-44.

\& 17 15. Dehdari T, Mergen T. A survey of factors associated with soft drink consumption among \& iv secondary school students in Farooj city, 2010. Journal of Jahrom University of Medical §।^ Sciences 2012; 9(4):33-9.

§19 16. Brownell KD. Does a" Toxic" Environment Make Obesity Inevitable? Obssity Management \&r. 2005; 1(2):52-5.

\&r 17. Faghih A, Anousheh M. Evaluating some of the feeding behaviors in obese patients visiting EY affiliating health centers. Hormozgan Med J 2008; 12(1):53-60. 
18. Paeratakul S, Ferdinand DP, Champagne CM, et al. Fast-food consumption among US adults and children: dietary and nutrient intake profile. Journal of the American dietetic Association 2003; 103(10):1332-38.

19. Timperio AF, Ball K, Roberts R, et al. Children's takeaway and fast-food intakes: Associations with the neighbourhood food environment. Public health nutrition 2009; 12(10):1960-64.

20. Pour Mahmoudi A, Akbar TabarTuri M, Pour Samad A, et al. Determination of peroxide in the oil consumed in restaurants and snack bar Yasuj. Journal of knowledge 2008; 13(1): 116-123 [In Persian].

21. SadrizadehYeganeh H, AlaviNaein A, DorostiMotlagh A, et al. Obesity is associated with certain feeding behaviors in high school girls in Kerman. Payesh Quarterly Summer 2007; 6(3): 193-199 [In Persian].

22. Greger N, Edwin CM. Obesity: a pediatric epidemic. Pediatric Annals 2001; 30(11): 694700.

23.Ghaffari M, Gharghani Z.G, Mehrabi Y, et al. Premarital sexual intercourse-related individual factors among Iranian adolescents: A qualitative Study. Iranian Red Crescent Medical Journal 2016; 18(2): e21220.

24. Kim KW, Ahn Y, Kim HM. Fast food consumption and related factors among university students in Daejeon. Korean Journal of Community Nutrition 2004; 9(1):47-57.

25.K. M. Harris, P. Gordon-Larsen, K. Chantala, et al. "Longitudinal trends in race/ethnic disparities in leading health indicators from adolescence to young adulthood," Archives of Pediatrics \& Adolescent Medicine 2006; 160(1):pp. 74-81.

26. I. Ajzen, "The theory of planned behavior," Organizational Behavior and Human Decision Processes, vol. 50, no. 2, pp. 179-211, 1991.

27. P. Branscum and M. Sharma, "Using the theory of planned behavior to predict two types of snack food consumption among Midwestern upper elementary children: implications for practice,” International Quarterly of Community Health Education 2011; 32(1): pp. 41-55. 
¿o. 28. Seo H-s, Lee S-K, Nam S. Factors influencing fast food consumption behaviors of middleso) school students in Seoul: an application of theory of planned behaviors. Nutrition research and sor practice 2011; 5(2):169-78.

sor 29. Hewitt AM, Stephens C. Healthy eating among 10-13-year-old New Zealand children: s० $\leqslant$ understanding choice using the theory of planned behavior and the role of parental influence. ¿oo Psychol Health Med 2007; 12:526-35.

¿or 30. Didarloo A, Shojaeizadeh D, EftekharArdebili H, et al. Factors Influencing Physical Activity sov Behavior among Iranian Women with Type 2 Diabetes Using the Extended Theory of Reasoned soג Action. Diabetes Metab J 2011; 35(5): 513-522.

so9 31. Kim KW, Ahn Y, Kim HM. Fast food consumption and related factors among university $\varepsilon 7 . \quad$ students in Daejeon. Korean J Community Nutr 2004; 9:47-57.

¿71 32. Yarmohammai P, Sharirad GH, Azadbakht L, et al. Assessing predictors of Behavior of High ¿tr School Students in Isfahan on Fast Food Consumption Using Theory of Planned Behavior. ¿тr Journal of Health Systems Research 2011; 7(4): 449-59.

ะฯ 33 . Brisling RW. The wording and translation of research instruments. In: Loner WJ, Berry JW, ¿70 eds. Field Methods in Cross-cultural Research. Beverly Hills, CA: Sage; 1986:134-164.

¿ 7 34. Kim KW, Ahn Y, Kim HM. Fast food consumption and related factors among university \& TV students in Daejeon. Korean J Community Nutr 2004; 9:47-57.

¿71 35. Sanaye S, Azarghashb A, Derisi M, et al. A survey on knowledge and attitude of students of \&79 ShahidBeheshti University of Medical Sciences toward fast food. Scientific Journal of the \&v. Medical Council of the Islamic Republic of Iran 2016; 34(1):23-30.

\& $v 1$ 36. Driskell JA, Meckna BR, Scales NE. Differences exist in the eating habits of university men ¿Vr and women at fast-food restaurants. J Nutres 2006; 26(10):524-530.

¿Vץ 37. Morse KL, Driskell JA. Observed sex differences in fast-food consumption and nutrition $\varepsilon \vee \varepsilon$ self-assessments and beliefs of college students. Science Direct Journal, Nutrition Research \&vo $2009 ; 29(3): 173-179$. 
¿vı 38. Aoki K, Shen J, Saijo T. Consumer reaction to information on food additives: evidence from \&\V an eating experiment and a field survey. J Econ Behav Organ 2010; 73:433-8.

\& $\vee$ 39. Stern T, Haas R, Meixner O. Consumer acceptance of wood-based food additives. Br Food J \&マ9 2009; 11:179-95.

¿^. 40. Kim H, Kim M. Consumers' awareness of the risk elements associated with foods and ¿A information search behavior regarding food safety. J East Asian Soc Diet Life 2009; 19:116-29.

zAr 41. Seo S, Kim OY, Shim S. Using the theory of planned behavior to determine factors \&AT influencing processed foods consumption behavior. Nutrition Research and Practice 2014; ¿^ะ 8(3):327-335.

¿10 42. Back BS, Lee YH. Consumer's awareness and policies directions on food additives-focusing ¿^ฯ on consumer information. J Consum Stud 2006; 17:133-50.

¿Av 43. Mirkarimi K, Mansourian M, Kabir MJ, et al. Fast Food Consumption Behaviors in High¿^^ School Students based on the Theory of Planned Behavior (TPB). Int J Pediatr, 2016; 4(7): 2131$\varepsilon \wedge 9 \quad 42$.

ะ१. 44. Murnaghan D A, Blanchard CM, Rodgers WM, et al. Predictors of physical activity, healthy ¿9) eating and being smoke-free in teens: A theory of planned behavior approach. Psychology and ¿qr Health 2010; 25:925-941. Doi: 10.1080/08870440902866894

¿१ฯ 45. Julie Lynn Fudge. Explaining adolescent behavior intention to consume fast food using the $\varepsilon १$ \& theory of planned behavior. Dissertation Submitted to the Graduate Faculty Of the North Dakota ¿9० State University Of Agriculture and Applied Science. 2013.

¿97 46. Stefanie A, Chery S. Applying the theory of planned behavior to healthy eating behaviors in ¿१v urban Native American youth. International Journal of Behavioral Nutrition and Physical ¿9^ Activity 2006; 30(3):1-10.

¿१९ 47. Dunn K, Mohr Ph, Wilson C, et al. Determinants of fast food consumption: an application of o.. $\quad$ the theory of planned behavior. Appetite 2011; 23(57): 349-57. 
0.1 48. Ebadi L Rakhshanderou S, Ghaffari M. Determinants of Fast Food Consumption among

0.r Students of Tehran: Application of Planned Behavior Theory. Int J Pediatr, 2018; 6 (10): 8307o.r 8316.

๑. 49. Pender NJ, Murdaugh C, Parsons MA. Health promotion in nursing practice. 4th edition. ๑. U Upper Saddle River, NJ: Prentice-Hall Health Inc 2002; P: 250-55. 